\title{
The design and construction of the Calder Bridge on the M1 motorway
}

\author{
E. W. H. GIFFORD, M. V. WOOLLEY \& A. A. W. BUTLER
}

\section{The Chairman}

It is indicated in $\S 19$ that the end blocks are prestressed in three directions. I took this to mean the transverse stressing of the end beam on which the precast planks stand; nothing, however, appears on Fig. 8. Can the Authors clarify?

81. I was interested in the toothed surfaces between the units 'precast', as it were, on the falsework. I would like to know why they were toothed. Did the Authors carry out any tests? This cannot have been an inexpensive construction, and it seems to me that some justification should be given for having such detail.

82. The Authors say later that any jointed construction in the beams over the piers would be inadequate in strength. Can they give the grounds for this statement?

83. The Authors, in $\S 36$, state that the relaxation of the wire did not exceed $7 \%$. I may be mistaken in my dates, but I would have thought that wire with $3 \%$ relaxation was available at that time.

84. The encasement of tendons was one of the points which for some time exercised the minds of those who sit on CP 115 as to whether it was necessary to have any further protection, as clearly the casing of the tendons must be unstressed. Although one Author has said that there were no visible cracks, this does not mean that there were no cracks. Have the Authors given any thought to this matter, and what is their view? There are not enough case histories of this type of construction to formulate the right sort of guidance in a code of practice.

85. I was most interested in the various analyses done for the prestressing of the end blocks vertically. It would be useful to know which of the values of the envelope, found from all the various work done, was used.

\section{Mr F. A. Sims, West Riding County Council}

I would like to comment on the plausibility of future competitions from the point of view of the amount of work involved in them. If one examines the effort not only of the panel, the Ministry of Transport and ourselves but that of the competitors in submitting their entries, it must be considered whether the effort is justified, especially when the design amounts to about 120 man years.

87. I find the Calder Bridge of particular interest in its method of support using three bearings. We had a railway bridge about $300 \mathrm{yd}$ from the Calder Bridge, with identical subsidence conditions, and we adopted a single span portal with three-point support with short approach spans. This was developed quite independently but is a very similar solution to the same problem.

88. I think that the structural form of the Calder Bridge provides an almost ideal solution to the three-dimensional problem of mining subsidence. How much racking or 'scrubbing' movement could the roller bearings at the south piers accommodate if differential lateral horizontal movement occurred? Clearly, under subsidence this effect can take place. Probably the large span helps in this case.

89. In $\S 7(a)$ of the Paper, the Authors state that an alternative position for the bearings would have been at the top of the piers. It would seem this would require a reduction in width between bearings, which would have reduced the factor of safety against overturning. On this account alone bearings at the base would seem to be preferred.

Paper published: Proc. Instn civ. Engrs, 1969, 43 (August) 527-552. 
90. I note also that additional prestressing is provided at mid-span. Could the Authors comment on whether additional counter-weighting of the side spans would have overcome the need for this, or whether prestressing was more economic? In $\S 32$, the Authors state that stresses in bending were limited to $2000 \mathrm{lb} / \mathrm{sq}$. in. It seems this is for $7500 \mathrm{lb} / \mathrm{sq}$. in. concrete. Why were the higher stresses not used? Were the stresses in the webs more critical? Perhaps the Authors could say if there was any advantage in making the main beam concrete of $6000 \mathrm{lb} / \mathrm{sq}$. in. quality.

91. With regard to the construction, it seems that a considerable effort was put into the adjustment of the individual sections, which each weighed 200 tons, to bring them to line and level. I should like to know whether the Authors now feel, having carried out the exercise, whether some additional steel reinforcement to cater for the construction stresses and casting to a predetermined profile would, perhaps, have been preferable.

92. I was most interested in the spring steel inserts in the deviators. I wonder whether the Authors specified a particular hardness for the spring steel. In the Wentbridge Viaduct we used spring steel strip inserts in the deviators. At that time I tried to arrange the spring steels which were harder than the strands themselves. In my view, this would prevent biting into the spring steel strips and twisting out, which, I think, occurred on the Narrows Bridge. I think that the hardness which we used was about $370 / 420$ VPN.

93. I was interested in the information given on friction losses with the $360 \mathrm{ft}$ long external cables. The Authors quote $13 \%$ average, of which $9 \%$ occurred in the end blocks, which I think were about $6 \mathrm{ft}$ long, although I could not find a figure for this in the Paper, with $59^{\circ}$ deviation in the cable path.

94. In this respect, it is interesting to compare other bridges. The Wentbridge had external cables $480 \mathrm{ft}$ long, $1 \frac{1}{8} \mathrm{in}$. dia. strands and their average friction loss was about $10 \%$, of which $6 \%$ occurred in the end blocks, which were $6 \mathrm{ft}$ long. The maximum deviation was $33 \%$. It is interesting to note that we also got about $9 \%$ friction loss in certain of the end block ducts. In our case it would have been preferable to use larger dia. ducting through the end blocks. I am not sure what the clearance was in the Authors' case.

95. With regard to the difficulties on temporary works mentioned in the Paper, these are major structures in their own right, albeit temporary. My concern is that many specifications, including national ones, class such structures under formwork, and merely call for them to be adequate to form and to support the concrete. In my view, a clear distinction must be drawn between the forms and the temporary construction stagings. I do not think that temporary stagings have been adequately covered in many specifications.

96. The conditions of contract are quite clear on the contractor's responsibility or temporary works, and I am not seeking to relieve him of any of his responsibilities. I do, however, request that greater guidance be given to contractors in specifications on the standards required in the design and execution of the temporary works, particularly the sort of stagings we have seen for major arches, etc.

97. Where no codes of practice exist for temporary works we should use codes of practice and standards that are available for permanent works and these should be clearly indicated to the contractor in a document. In addition, the test certificates must be supplied in respect of materials and component parts used in temporary stagings, whether they are new, old, or secondhand. Where test certificates cannot be obtained, I think that tests to destruction of representative samples are quite in order.

98. Whilst committees are sitting to produce standards for temporary works, I see no objection, in their absence, to using British Standards and codes of practice for permanent works. We have operated this practice in the West Riding for some time.

99. I have no doubt that there will be criticisms from certain quarters that the 
design of temporary works on the basis of codes of practice and British Standards for permanent works would entail additional expense. In my experience, however, one rarely finds the primary members severely at fault. It is usually in the details, such as the connexions and so on, where major weaknesses lie. Perhaps the Authors would comment on this.

\section{Mr D. J. Lee, G. Maunsell \& Partners}

The design and construction of the Calder Bridge has a somewhat long and involved history and the Authors are to be congratulated on solving the difficult problems involved.

101. I should like to say a few words on the subject of the original Calder Bridge competition. The competition brief posed interesting technical problems and in my opinion a straightforward solution of the problems outweighed considerations of startling appearance. As it turned out, the judges were not able to recommend a clear winner and recommended that the first prize be divided equally between the Authors' design and one prepared by my firm. The two winning designs had quite striking similarities, the main difference being that the Authors' design had three spans whereas the Maunsell/Poulson design relied on a simple span supported on three bearings, two on one side and one on the other. Fig. 20 shows at the top the design which the Authors submitted for the competition. Below it is the Maunsell entry and at the bottom is the structure as built. It can be seen that there has been considerable development of ideas, indeed almost a hybrid section has been evolved from

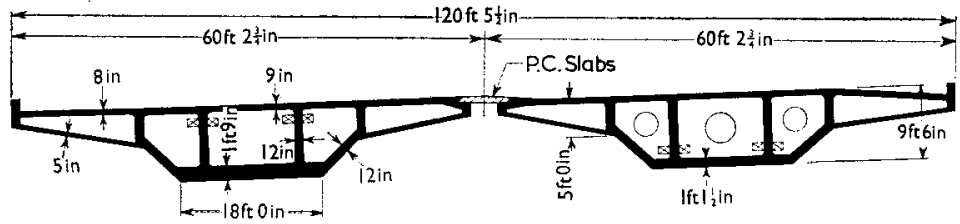

JONT WINNING ENTRY BY A.AW. BUTLER AND M.V. WOOLLEY IN ASSOCIATION WITH E.W.H.GIFFORD AND PARTNERS

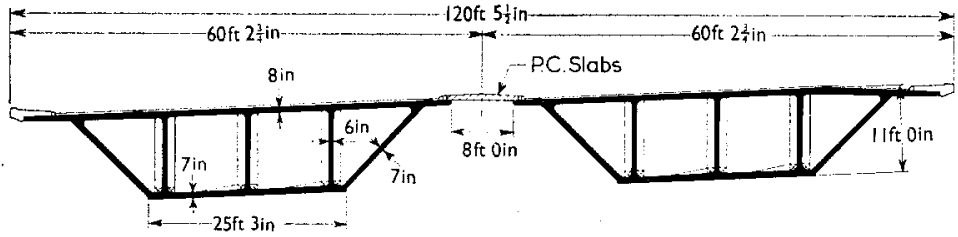

JOINT WINNING ENTRY BY G.MAUNSELL AND PARTNERS AND J.G.L.POULSON

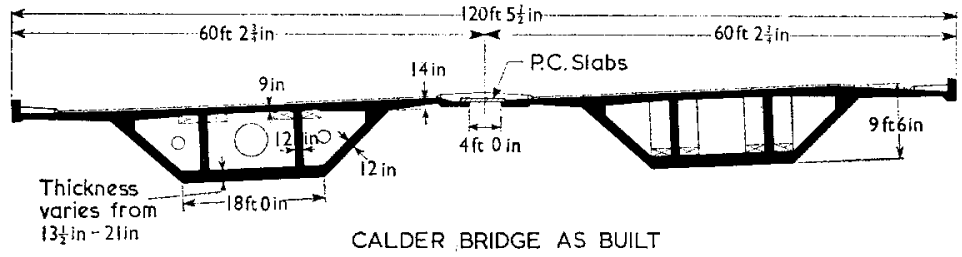

Fig. 20. Designs for the Calder Bridge competition 
the winning entries. I would like to ask the Authors if they revised their scheme themselves or were requested to do so by the Client-perhaps either the Ministry of Transport or the West Riding County Council.

102. The second point relating to the competition was the question of economy and costs. The judges quite specifically stated in their report that the cost of the Authors' entry was likely to be significantly more than the other first prize winner but its appearance was preferred. Whilst the awards were made in concordance with the stated aims of the competition, it is interesting to note that public money has been spent in building a bridge which was expected to be dearer than another design. I should be glad if the Authors will comment so that we may all use the information in persuading clients to spend a little more money occasionally on beautification.

103. One general remark about design competitions. As one disposes of the copyright as a condition of entry one has to bear this in mind in producing the design. My remark does not apply to design and build competitions when we always make every effort.

\section{Mr K. J. Prangnell, Costain Civil Engineering Ltd}

I should like to comment on the collapse of the secondary south span, referred to in $\$ \S 44-47$. The steel beams, which were confused, were very close in size. The mild steel beams were close to their upper rolling margin and the high tensile ones were close to their lower margin. Perhaps a prominent rolled-in identification on their webs would have proved rather more effective than the obliterated paint marks. I am not convinced, however, that the whole responsibility for the mechanism of the collapse can be blamed on these capping beams. The tight construction space meant there were several parts of the temporary structure which were highly stressed and were not easily capable of dealing with the shock loads resulting from the unintended movement of the 220 ton units.

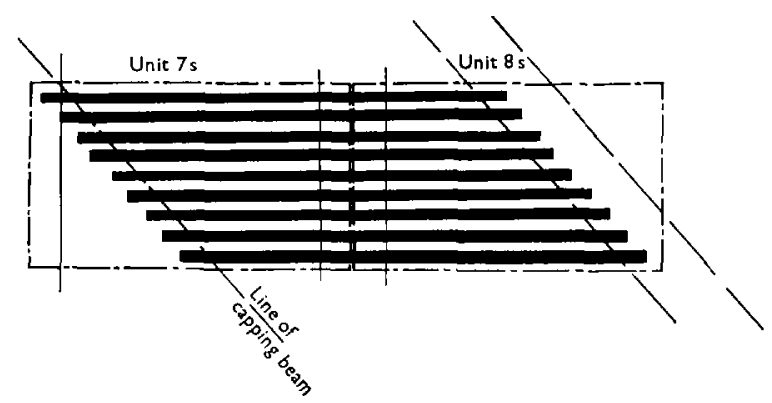

Fig. 21. Temporary supporting beams of the spans

105. The temporary supporting beams of the spans were running along the lines illustrated in Fig. 21. There were nine of them covering the width from one side to the other. When the units were cast, they were cast square to the bridge and, of course, the ends of them were skew relative to the supports of the beams. The supports provided by the capping beams were parallel with the river.

106. We thus have the situation that if one considers the strength of the supporting beams relative to the end of any particular 220 ton unit, each supporting beam would provide a deflexion or effective apparent stiffness varying from that of its neighbours, which meant that each unit was subject to a rotation about an axis which was skew to the bridge, skew to the river, and skew to practically everything.

107. The problem of calculating the behaviour of the units and the beams under the casting and the jacking processes was affected by the compression characteristics of 
the packers, the deflexion of the piles under the loads resulting from the jacking and, indeed, the sequence of jacking up the units. The analysis proved to be very complex and one could not hope that it would be exact, although we eventually arrived at an answer which was sufficiently close that a reconstruction of the fallen span and the completion of the other spans could be carried out.

108. A propos of this, I should like to reinforce Mr Sims's remark and ask whether the Authors would reconsider the use of this jacking process and use the alternative means of a predetermined formwork profile plus the achieving of the final deck profile by an adjustment in the height of webs, etc., which would probably amount to a maximum of 1 in.

109. On behalf of contractors, I would like to respond to $\mathrm{Mr}$ Sims. We use British Standards and we do our design to the best of our ability. The requirements of temporary works are rather different from permanent works. We do not, largely for financial reasons, shelter behind blanket factors of safety. Naturally, our factors of safety are taken to be smaller because of the temporary conditions. Therefore we are, perhaps, working on a slightly smaller margin. However, we use them and we try to use the best practice possible.

110. I would like to go on to one thing relative to the layout which is shown in Fig. 1 of the Paper. It is apparent that with a permanent clear height specified at $20 \mathrm{ft}$ above the river level and a construction clearance of $18 \mathrm{ft} 6 \mathrm{in}$., there was little room to cope with the square clear span requirement of $50 \mathrm{ft}$ which we were given. In fact, the main span beams were 36 in. $\times 12$ in. closely spaced under the bridge soffit, and they gave considerable deflexions under load.

111. If an opening of $30-40 \mathrm{ft}$ in width skew to the river but square to the bridge had been permitted, the problems of construction would have been much eased and I suggest that the light traffic on the river would not have been much more troubled by this restriction than by the existing $35 \mathrm{ft}$ locks of the Broad Cut half a mile upstream and the Thorne Cut rather more than half a mile downstream.

112. This situation is not unique and I would like to make a plea that statutory bodies be urged by their consulting engineers to set as generous allowance on construction clearances as tolerable traffic interference will permit during the limited construction period. It might be borne in mind that easier construction allows faster operation and, possibly, shorter occupation times.

\section{Mr D. R. Moore, Stress Engineering Services Ltd}

I wish to add to what $\mathrm{Mr}$ Sims has said on the friction losses in the anchor block and separators, as mentioned in $\$ 66$.

114. Strain gauges were used to measure the strand loads between the anchor blocks and the saddles, between the saddles and the first separator, and in the centre of the span. Two strands were instrumented; three strain gauges were set at each point, on alternate outer wires of the strands. The strain gauges at each point were connected in series to eliminate bending errors. As the strands were exposed inside the box, the fixing of the gauges was fairly easy, although it could be done on ducted cables. Strain gauge readings were taken as the jack load was increased in increments of 10 tons up to 60 tons and again at 64 tons. Final readings of relaxation were taken when the jack was locked off.

115. The strain values were corrected to load in the following manner: a sample $12 \mathrm{ft}$ length of strand was fitted with six strain gauges and loaded in a class A testing machine at British Ropes Ltd. Readings were taken from the strain gauges and on the British Ropes 50 in. rope extensometer for load increments of 5 tons. This instrument had been used to measure the $E$ value of the strands used on the site. The usual load strain curve for a strand was obtained for both the extensometer and for the strain gauges-a straight elastic part followed by a curve after the limit of proportionality is reached. The graph of strain gauge readings against extensometer was a straight line, showing that it is the steel which yields and not the strand structure. 
116. The strain gauge readings were consistently $4 \%$ lower than the extensometer readings as the extensometer registers steel strain plus extension of the lay of the strand. An addition of $4 \%$ was therefore given to all the readings and these results were used to measure the load from the load extension graphs provided for the strands used on the site.

117. A final correction was needed as the strand was under initial tension before strain gauges were applied. The initial tension was derived from graphs of the above results. The initial straight part of the graphs of each measuring station crossed the axis at a negative load equal and opposite to the initial tension. These were added to the first figures to give actual loads at each station and from these the friction losses mentioned in $\S 66$ were calculated.

118. On the first stressing of the first strand, the measured loads were much lower than anticipated. This was found to be due not to high friction losses, but to faulty calibration of the load cell used to measure the jack loads. This had been calibrated in compression. When calibrated in a tension machine, it was shown that the calibration altered according to the eccentricity of loading. This has since been noted on two or three more different types of load cell. Sleeves were placed inside the bore of the load cell to bring it nearer to the strand dia. This reduced load cell errors to a tolerable level. Initially, it could have read $6 \%$ high, losing 4 tons in the 65 ton tension applied. Care must therefore be taken to calibrate a load cell in the conditions in which it is to be used. This technique provides a convenient way of measuring the friction losses and strand stresses. It is most easily carried out on exposed strands and strands with large dia. external wires. The flat surfaces of die-form strand are the simplest to instrument.

119. It can be used on ducted strands if sufficient concrete can be chased out to expose the strand for bonding the gauges, and to allow for movement as the strand extends. Alternatively, the strain gauges can in some cases be bonded to a strand before concrete is poured. The minimum outside wire dia. to which a strain gauge can be bonded is $0.025 \mathrm{in}$. but for on-site work a practical limit is probably $0.075 \mathrm{in}$.

\section{Mr J. D. Steel (M)}

Had the Ministry of Transport got the local river authority to agree to allow the river to be diverted into two channels, the bridge could have been built with two spans instead of the one long one. In relation to the highly stressed ends of the 'box type' construction, i.e. the cable anchorages, I find it rewarding when considering the design of such details to contemplate what possible means of solution the mechanical engineer would adopt, as distinct from the civil engineer! Thus, for example, it might be possible to prestress say, a connecting rod, for an internal combustion engine.

121. In the same way, have the designers of the bridge considered the possibility of cast iron or fabricated steel ends to the bridge, instead of the complexity of vertical reinforcement that had been adopted?

122. Another interesting fact arises out of considering the design from the viewpoint of a mechanical engineer: it concerns the 'torsion box' concept adopted in the design of the bridge.

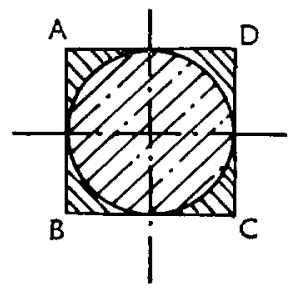

Fig. 22. Section of a round shaft and an enveloping square shaft 
123. In such a connexion, it would seem that in comparing the properties of 'square' and 'round' shafts with respect to torsional, that a $1 \mathrm{in}$. dia. shaft might be stronger than a 1 in. square shaft (I put this to students as an interesting item for research) since the 'nibs' that go to form the corners of the square shaft with respect to the round, considerably alter the stress pattern, especially at the corners where stresses are intense (Fig. 22).

124. In the same way, there might be reason to suggest that the 'corners' of a box in torsion, with respect to the criterion adopted for the design of the bridge, might have been of some other shape.

\section{Mr P. Elliott, Ministry of Transport}

The Paper gives information on all aspects of the design and construction, and I congratulate the Authors upon it. It includes information also on the unfortunate collapse of the formwork which resulted in loss of life and to which previous speakers have referred. I think it is right that experience gained at high cost in this way should be passed on, and I would like to commend the Authors for recording in detail the primary causes of the accident so explicitly. There are lessons in this for all of us.

126. In reply to a previous speaker who has referred to the accident and the collapse of the steel beams, I agree with the Authors that the primary cause which triggered the accident was the collapse of the web of the 18 in. $\times 6$ in. capping beam. I personally think that the difference in the grade of steel, which has been mentioned in the Paper, was a fairly secondary issue. I say this because although it was a mild steel beam, tests showed that it was well beyond the guaranteed minimum yield of $16 \mathrm{ton} / \mathrm{sq}$. in. for mild steel. This is common in webs of beams of a thickness of about $\frac{3}{8}$ in. I think, therefore, that this was a relatively secondary issue. I fully support the view expressed by Mr Sims that it is attention to detail which is important in these matters.

127. If I may comment briefly on the price of the bridge, which is referred to in $\$ \$ 42$ and 76 it was a joint decision of the Ministry that the Calder Bridge should be included in the Donnington to Wakefield section of the M1 motorway. This, as the Authors have pointed out, did not result in the lowest price for the bridge. A lower tender, which had in fact a higher overall price for the motorway contract, was submitted. Nevertheless, I think that it was undoubtedly the right decision to include the bridge in the motorway contract and, despite the fact that a lower price was submitted for the bridge, the inherent economy of the Authors' design is reflected in the price that was finally achieved, i.e. $£ 9 / \mathrm{sq}$. ft of carriageway area.

128. I was interested in the photoelastic method of analysis employed for the derivation of the stresses due to eccentric live load in the multi-cell box section. I would like the Authors to comment on the order of accuracy achieved by this method in comparison with computed results.

129. The tripod support has already been referred to. The Authors adopted this having regard to the requirements for substance which were stringent, and they went for the simplest and most direct solution to this problem. Stability is fundamental to this approach, and perhaps the Authors could confirm that they were able to achieve a higher stability factor in the final design compared with that at the stage when it was submitted to the competition.

130. The decision to construct the bridge using discrete precast units rather than an in situ monolithic construction has already been referred to by $\mathrm{Mr}$ Sims and others. Perhaps the Authors could confirm my belief that this decision partly stemmed from the requirements of long span of the staging across the river. These requirements, which called for a $50 \mathrm{ft}$ clear span at midstream in the Calder River were requirements of the River Board and not of the Ministry of Transport or of the agent authority. I think that this decision, which naturally resulted in a very much longer span measured on the skew, partly contributed to the decision to construct the bridge using discrete units which were subsequently jacked into position. Perhaps the 
Authors could comment on this because, if this is true, it illustrates the impact that temporary staging requirements have on the construction of the final bridge and, indeed, on the design.

\section{Mr J. L. Paisley, Ministry of Transport}

I wish to comment on the competition. I was not concerned in its setting up, but I think there was a feeling at that time that perhaps British designs were becoming a little stereotyped and we should give opportunities for the inventive genius of engineers to show itself. One's view of a competition depends on whether one wins, and for the Authors it was a very good competition. For our part, it gives us an elegant design which does its job satisfactorily.

132. I would not, however, regard the competitive element as a starter for the generality of the bridges that we have to tackle. There must be a very considerable waste of design office and checking effort involved in weighing up the relative design merits. An earlier speaker suggested that engineers do not bring out their best designs for competitions of this sort.

133. My second point concerns temporary works. I was, unhappily, brought into the discussion at the time of the collapse of the staging. There is no doubt that this question is an extremely difficult one. The conditions of contract are quite explicit - the responsibility is the contractor's. The contracting side have always maintained that it is the engineer's job to say what he wants built and to leave them to get on with it and build it. Nevertheless, the engineer has responsibility for the adequacy of what the contractor does but, at the same time, the responsibility is not taken away from the contractor.

134. I do not know that we have got the right answer yet on this problem. We had some quite involved and lengthy discussions as to how this might be achieved in the committee, dealing with the conditions of contract. Someone suggested that if the engineer wants further strengthening work or modifications to temporary works put up by the contractor, he should pay the additional cost. I do not like that idea at all. To me, it is a complete 'non-starter'. It is fair that the responsibility rests with the contractor and that the expense of his temporary works will be reflected in what he expects to be paid for the job as a whole.

135. Mr Sims mentioned the possibility of requiring the temporary works to conform to the same standard as the permanent works, and this is an attractive suggestion; if carried to its conclusion, it could remove these difficulties. One feels, however, that there would need to be some circumscribing if we are to get advantage from the contractor's expertise in temporary works and the possibility of working to smaller margins and finer limits.

136. I have been inclined to think that there are two cases here. There is the generality, which does not worry us, but then there are the special structures-and perhaps Calder Bridge is of this type-where the constraints are considerable. Certainly, a solution would be for the engineer to design the temporary works and to have them priced in the bill. This might cost us more, it might not be very different from Mr Sims's suggestion, but it would relieve the engineer very considerably. He would be certain of his temporary works ab initio. It would certainly take any worry off the contractor's shoulders.

137. I repeat that the question of substantial temporary works on bridges of this type and similar structures is a problem which merits a lot of further consideration.

\section{Mr L. A. Probert, West Sussex County Council}

I notice the Authors had ordinary reinforced solid concrete piers roughly $18 \mathrm{ft} \times 10 \mathrm{ft}$ with a base which was prestressed. Perhaps they could explain how they combated shrinkage in these large piers and what percentage of reinforcement was provided transversely. 
139. I should like to reinforce Mr Elliott's question regarding the criteria with which the Authors judged that the structure should be cast in segments rather than monolithically. What degree of movement or deffexion do they consider to be critical in determining that decision?

140. The Authors have said that the deck tolerances between units were greater than $\pm \frac{3}{8}$ in. and as $I$ have heard it argued that machine laying of $\frac{5}{8}$ in. sand/asphalt regulating carpet is incompatible with the normal concrete deck tolerances of $\pm \frac{3}{8}$ in., I should be pleased to hear whether the material was machine or hand laid on this bridge.

141. In $\S 32$, the Authors give a principal tensile stress of $175 \mathrm{lb} / \mathrm{sq}$. in. under HA loading and $220 \mathrm{lb} / \mathrm{sq}$. in. under $\mathrm{HB}$ loading. What references do the Authors have for determining their maximum permissible tensile stresses? I would also like to know whether they gave the contractor the loads on each of the precast sections, both in the dead load condition and under prestress. Did these loads turn out to be correct when they were subsequently checked? My own experience has been that due to the variation in ' $\mathrm{E}$ ' for concrete it is virtually impossible to give both level and load.

142. In Fig. 4 is shown the method of construction of the hollow box where the sides are poured after the base and, subsequently, the deck slab itself. How much differential shrinkage did the Authors allow for that type of construction? Also what tests did they carry out to determine the coefficient of shrinkage of the aggregates used?

143. The Authors mention the cantilever section and the scaffolding tubes being released individually. How were they re-tightened in order to attain the same load? Also, a considerable number of recordings of gauges, etc. were necessary during the construction. I should like to know how many staff were involved in doing this and whether there was a considerable delay to the contract.

144. I have recently had experience of Young's modulus of elasticity for Dyform strand. Although the manufacturers tell me a certain value and give a tolerance in their case of $\pm 1.5 \%$, I have found this has been in the order of $\pm 5 \%$. What is of far more concern is that this variation occurs within a reel of strand. I ended by taking the average for the output of the whole of last year's production, but I should be interested to know how the Authors solved the problem.

145. The Authors make no mention of the distribution of prestress through the flanges over the piers. Model tests were carried out at the Mancunian Way where it was determined that the flanges were virtually ineffective over the piers. Full scale loading tests carried out on the same structure ${ }^{1}$ gave different results and conclude that one should take $90 \%$ of the second moment of area over the piers. What distribution did the Authors take over their piers and what section was used to determine the position of the neutral axis?

\section{Mr J. R. Lowe, Partner, E. W. H. Gifford \& Partners}

I want to disagree with something that my Partner has said. I fear that the first half of the second sentence of $\$ 25$ will shortly be quoted in isolation, i.e., 'Unbonded prestressing cables are not suited to segmental construction'; the sentence actually continues, 'as continuous mild steel reinforcement cannot be provided to supplement the lower load factor'.

147. The Authors are here assuming that mild steel reinforcement is necessary for this purpose, but in fact an adequate load factor can be obtained with unbonded prestressing cables in segmental construction by using sufficient cables.

148. Concerning competitions, I believe that if one enters competitions wholeheartedly and puts in one's best designs, one gains something whether one wins or not. Competitions have enabled us to study certain techniques, which we have later put into practice.

149. Furthermore, those of us who are keenly export orientated, find that in many 
parts of the world the only possible way to get a foothold is by preparing competitive designs for contractors for 'design and construct' tenders. One often has to submit these designs against intense competition from the continent and within an extremely short period of time. Experience of the Calder Bridge type of competition has been very beneficial to us in this respect.

\section{Mr M. B. Jacob, Sir Bruce White. Wolfe Barry \& Partners}

I should like to know whether the Authors have ever noticed vibrations in unbonded strand and whether they consider the possibility of fatigue-corrosion should be taken into account.

151. The temporary works and centering have been dealt with already and I support the view that in certain special structures the Engineer should take full responsibility for the design, detailing and inspection of temporary works. I should like to know from the Authors what consideration was given to the design of the centering during the development of the main design and in what way they felt that the main design was restricted by the need for centering.

Mr M. H. Rees, Watermeyer Legge Piésold \& Uhlmann

I am rather bothered about the mining subsidence question. It all started with the competition requirement of a differential settlement of $1 \mathrm{ft} 6 \mathrm{in}$. and an overall settlement of $4 \mathrm{ft}$. Where did these figures originate? Were they substantiated before the consulting engineers prepared their design? It has pretty fundamental effects on the question of stability, which Mr Elliott has also mentioned.

153. The science of estimating subsidences at ground level and their relative effect on foundations spaced apart is a very inexact one indeed and depends on the method of mining, height of face, depth to the stoping, method of stoping, the direction of mining and a number of other different factors. Subsidence may be divided into continuously progressing settlement and sudden settlement, which can be embarrassing.

154. How did the Authors arrive at this $4 \mathrm{ft}$ ? Was it a figure given by the National Coal Board? Did the county authority determine it? Who is responsible if it is exceeded and the bridge falls down? Is there an agreement between the National Coal Board and the county authority? Did the consulting engineer accept this in terms of the engineering consequences?

155. If one could briefly show that in the skew span, shown in Fig. 23, which was divided into the two half bridges with the bearings in their relative positions, and then isolating diagrammatically one of these half bridges and calling it a right bridge for the moment to illustrate the point, we are then faced with the Authors' fulcrum lines which are very slender indeed and very finely spaced. If one takes a section through the centre of gravity, and in that section one has the bridge and its centre of gravity and if one has these two fulcrum lines at quite a small distance apart, I know that I am exaggerating, but so also can mining subsidence exaggerate itself. It does not need much of a rotation before the bridge is head over kilter. Therefore, I query where the $4 \mathrm{ft}$ and the $1 \mathrm{ft} 6 \mathrm{in}$. originated and in doing so I suggest that the figures are something of a guess. It is all very well if subsidence is continuous (it is possible to jack) but in the event of sudden subsidence, which is possible in certain overburden, one could be in difficulty.

156. On the question of jacking, I do not altogether agree with $\mathrm{Mr}$ Butler that it is a simple matter. He rather waved it aside. My firm has been involved with jacking of similar orders of size of overhead viaduct piers for the same reason-mining subsidence - in another part of the world. It is by no means simple. One has to - put very careful thought into the design of the jacking system, even though the structure, as in the Gifford case, as in our own case, treating the structure as a rigid body, has a three-dimensionally statically determinate foundation system. This latter is a 'must' with all major subsidence problems. 

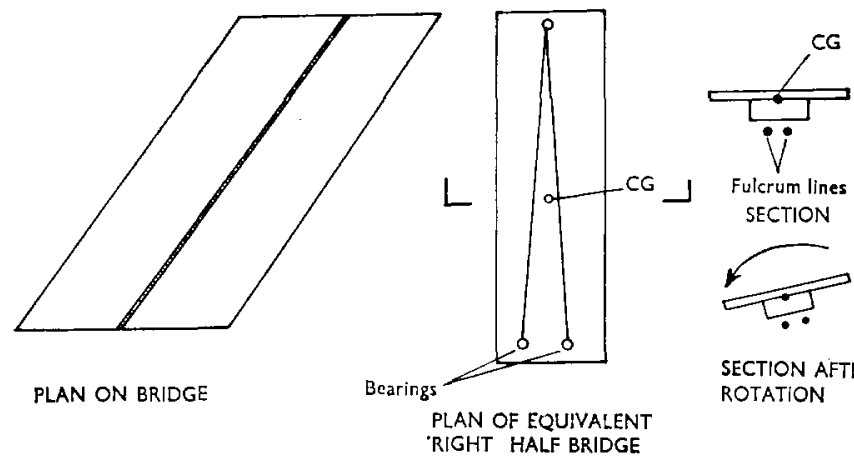

SECTION AFTER ROTATION

\section{Fig. 23. Skew plan}

157. Why did not the Authors put in a statically determinate jacking method? They have four jacking points per pier. Why not three? This makes life easier. The jacks have to supply two conditions. They must strain equally, and they must have equal load on them. These are two independent conditions not easy to arrive at.

158. Have the Authors a special jacking system? Where is it? Who operates it? Is it the county authority or a specialist subcontractor? Is it something that can be done in an emergency? Can these jacks be brought on to the site quickly? Are they there on the site?

\section{Written contributions}

\section{Mr H. Addison, Consultant}

Referring to the conditions of the competition, I note that according to $\S 3(\mathrm{a})$, first in order of importance was the appearance of the bridge. The question therefore arose, who were the people likely to be concerned with its appearance? They could hardly be the road users themselves, because when crossing the structure at motorway speed they would not realize that it was there. As for the viewers who saw the bridge as it appeared in Fig. 19, would they be very numerous? Was there much waterborne traffic along the river Calder?

160. Nevertheless, the reason why the appearance of the Calder bridge was of unusual interest was because this bridge was perhaps the final item in a remarkable series of bridges, comprising all those that had been built during the past half-century to carry trunk highways from London to Yorkshire and the North. No matter whether the bridges were elements of the reconstructed Great North Road-now the A1 road-or of the M1 motorway itself, the highway had to be carried across rivers such as the Great Ouse, the Nene, Trent, Calder, Don and Aire. If one could now successively examine these structures, they would tell a fascinating story of engineering evolution in the use of concrete, ranging from the 1928 Wansford bridge to the Wentbridge viaduct, and Ferrybridge viaduct, and the Calder bridge itself.

161. But there lies the difficulty: the ordinary motorist cannot himself study many of these bridges, because they are virtually inaccessible except to inquirers who are prepared to mount for themselves a sightseeing expedition.

162. That is why readers of the present Paper have welcomed the picture that the Authors have provided. These readers, moreover, if they have themselves driven along the M1 motorway and the A1 road and have observed the successive improvements that have been so much to their advantage, will hope that if a comprehensive account of this transformation should be published, it will include pictures of the notable bridges. 
Mr M. L. Cooper. Taylor Woodrow Construction, Ltd

I would like to state my admiration for the Authors who have produced a bridge design which gives a unique solution to the problem presented in the terms of reference for the competition. They were not the only competitors to hit on the idea of supporting the bridge deck on three bearings. The additional merit of their design is, however, that the necessary make up if and when jacking of the bridge becomes necessary, can be made without spoiling the lines of the bridge. It is hidden in the bearing well below ground level. The courage of the Authors in presenting this Paper, after the occurrence of the unfortunate accident during construction, is much to be commended.

164. There are several items on which I should like further information.

165. Would the Authors please clarify $(\$ 8)$, which beams are to be covered with a 14 in. thick layer of tarmacadam? Why should this be "considered to maintain a reasonably smooth road surface during subsidence movement'? Is this a reference to the disturbance of the road surface due to racking of the bridge with respect to the approach roads?

166. Could some further details of the temporary deck support works be supplied? What size of temporary steel beams were used to span the main gap which had a $50 \mathrm{ft}$ square span? After having had some experience of the trouble required to move heavy precast concrete beams by means of jacks, I would consider that it was worth spending a great deal of effort in lining up the shutters and compensating for deflexions in temporary supports, to avoid the necessity for jacking these enormous 220 ton units. Some hint is given in the text of the Paper of difficulties presented by the jacking operation. Would the Authors please say whether this alternative method was considered; or whether that was the intended method and the jacking was only necessary to compensate for unforeseen movement during construction?

167. I would be interested if the Authors would give details of their proposed arrangement for jacking up the entire bridge after subsidence. What size and number of jacks are planned for this? Has any special procedure been worked out? Would it be necessary to excavate in the towpath to gain access to the jacking points or has provision been made for access?

\section{Messrs Gifford, Woolley and Butler}

The Chairman questioned the location of the transverse prestressing in the end blocks. This is shown in Fig. 8. At the top left hand side of the cross section, a series of shaded ellipses represents ducts running skew to the longitudinal axis of the bridge. They are in the top of the anchorage, but due to the self weight effects of the end diaphragm, the effective prestress on the cross section is rather nearer the neutral axis of the section than the location of ducts would indicate.

169. The Chairman's next point concerned the toothed joint detail. Under ultimate conditions it was considered possible that cracks would concentrate themselves at the unreinforced joints rather than more evenly throughout the bridge in the region of mid span. It was necessary to maintain a torsional resistance under these conditions, and we felt therefore, that it would be an added factor of safety if we provided a mechanical lock as well as the more conventional bonded connexion. Hence the rather large castellations, which in the event were not so expensive; they were fairly quickly formed on the shutter and we were pleased to see them there. Had the unreinforced jointed construction been adopted near the piers, the permissible principal tensile stress would have been exceeded through the joint. In these areas reinforcement was necessary to cater for the principal tensions created by coexistent bending, shear and torsion.

170. Next, the relaxation question. Yes, there is strand available with lower relaxation. We used it in the pier bases, but $1 \frac{1}{8}$ in. dia. strand is not available at this low relaxation. Nevertheless, $1 \frac{1}{8}$ in. dia. strand has such a tremendous advantage for 
external strand construction in that one can reduce the cost of the separator plates and saddles very considerably and reduce the number of threading operations which would otherwise be required using a smaller diameter strand. We were very happy with the performance of the $1 \frac{1}{8}$ in. dia. strand on site.

171. The Chairman has asked about cracking of the strand casing concrete. The only important cracks would be those large enough to admit moisture, which if they had occurred would certainly have been visible, but micro-cracking was unimportant. The case histories that are available to the Authors are instructive and encouraging. The first is Narrows Bridge, completed ten years ago. Although a fine concrete casing was specified this was changed by a site decision to grout, to simplify construction. The cracks that, not surprisingly, occurred were later covered with neoprene paint with complete success. At Tasman bridge, completed in 1965 , the specification of a $\frac{3}{8}$ in. maximum sized aggregate with $0.45 \mathrm{w} / \mathrm{c}$ ratio and $1: 4$ cement/aggregate ratio was implemented and no visible cracks occurred then or since. We believe a similar specification was used at Hammersmith flyover with equal success. The shrinkage strain of the concrete bonded to the strand is partly offset by the loss of prestress in the tendon produced by the creep of the beam concrete, which results in a shortening of the deck.

172. The next point concerns the analysis of the end block. We eventually applied the $\mathrm{C} \& \mathrm{CA}$ values modified to take account of the fact that we had one large prestressing force and not a series of smaller ones. We were containing one 2000 ton prestressing force in each block and in addition had the deep beam effect. When it came to consideration of what happened outside the block itself, the C \& CA methods were of no help. This was where we had to resort to methods suggested by Leonhardt. $^{\text {a }}$

173. Mr Sims queried the need for the internal strands in the main span of the bridge. These could not have been eliminated by providing counterweighting since the design was finely balanced between cantilever moment and midspan moment and there was very little room for manoeuvre, either by increasing or decreasing the main cantilevers to adjust stresses. Stresses were at their optimum with the given configuration.

174. The internal strands in the bottom slab were there because it was possible by this means to increase the effective eccentricity of the total strand grouping. There were one or two extra strands over what was required precisely by the design. We lost one strand in one bridge and wires failed in two strands in the second bridge. The extra strands in the internal ducts available at midspan meant that we were able to maintain the total design prestress despite these losses.

175. Mr Sims quoted the stress of $2000 \mathrm{lb} / \mathrm{sq}$. in. He did not quote the fact that we worked to $2500 \mathrm{lb} / \mathrm{sq}$. in. under HB loading, which was the critical loading case which we had to consider. The allowable stresses were originally laid down in the Ministry of Transport competition documents. Had $6000 \mathrm{lb} / \mathrm{sq}$. in. concrete been used, it would have been overstressed in many places.

176. The hardness of the spring steel inserts was Rockwell C50-55.

177. Mr Sims also asked whether the effect of jacking of sections was worthwhile. If substantial clear openings are required in falsework, or temporary foundation settlement is likely, the provision of additional reinforcement would be inadequate. However, the effort of jacking and adjustment of sections was not great. $\mathrm{Had}$ the temporary works been of adequate strength to permit random adjustment of sections and had the sections been more accurate or the tolerances a little wider, then the jacking would have been a simple, uneventful operation. We are, therefore, satisfied that the method was the correct one for the site. It should be remembered that the deflexion on the temporary works on this scheme was 3 in.

178. Mr Elliott has suggested that the requirement for long spans arose from the requirements of the River Board and not the Ministry of Transport. He is correct in the sense that it was not the Highways Department of the Ministry of Transport, 
but it was in fact the Calder Navigation authority (not the River Board) who are part of another section of the Ministry of Transport. We were unable to persuade the Navigation Authority to reduce this requirement as we were assured that heavy commercial traffic used the canal. We subsequently discovered that the heavy traffic stopped at Wakefield and that virtually the only barge that used the river was the one that came to inspect the opening. There is no doubt that, had the navigational requirements been realistic, the complication of the flexible skew falsework would not have arisen.

179. Mr Probert has asked for a definition of the critical degree of falsework movement acceptable before using segmental construction. This may be defined by the extent to which it is practical to reinforce the unprestressed deck, particularly with regard to the cracking that might ensue in a comparatively lightly reinforced section.

180. In the context of this discussion we should mention that at the Narrows Bridge, ${ }^{2}$ Perth, we successfully used segments to avoid problems of deflexion of foundations and at Tasman Bridge ${ }^{3}$ we used segments in the main span beams for deflexion of temporary works. In both bridges, as described in the papers, large deflexion took place and the method was wholly successful. The units were smaller and the spans were right, but these were not the fundamental difficulties at the Calder Bridge.

181. Both Mr Sims and Mr Prangnell have mentioned the application of British Standards to temporary works. The Authors support $\mathrm{Mr}$ Sims completely in his view and agree also that the detailing of connexions is often a source of weakness.

182. The Authors do not understand Mr Prangnell, however, when he says that 'we' (presumably Costains) use codes of practice but do not 'for financial reasons, shelter behind blanket factors of safety ... . because of the temporary conditions'. Indeed they do not and this is precisely the point. Factors of safety are designed to cover insufficient knowledge of loading, errors of calculation and inadequate workmanship. As all these elements are present to a more marked degree in temporary works than in permanent, there would appear to be an excellent case for increased, rather than reduced, factors of safety. Lives are more important than 'financial reasons'.

183. The Authors believe that this problem of responsibility for the design of temporary works can only be solved by the contractor's full acceptance of this responsibility. Attempts by the engineer to design the temporary works would tend to reduce the contractor to a 'labour and materials' agent, which would be equally unwelcome to engineer and contractor.

184. Mr Paisley also refers to the advantages of the possibility of working to finer limits than given in codes of practice. I believe that the advantages to the owners are probably marginal and certainly not worth the risk.

185. Mr Jacob asks whether we have noticed vibrations in unbonded cables. We should point out firstly that the cables at Catder are encased in concrete and bonded and hence not subject to vibration. In structures with unbonded cables, however, there may be a danger of anchorage fretting due to combination of vibration, load variation and the notch effect of the anchorage. This is best avoided by grouting the length of tendon adjacent to the anchorage so that it is shielded from such effects. The Authors did consider the design of centering during the main design and did show a proposal in the competition, but the temporary works actually used were quite different and were solely those of the contractor.

186. The Authors were very pleased to find themselves in such good company as competition joint first prize winners. They were also pleased at the similarity between Mr Lee's design and their own.

187. Mr Lee's first point concerned the difference between the Authors' competition design and the final design as it emerged. We were not prompted in any way to alter the design, but the alteration resulted from the opportunity to consider the problem in depth. It also sprang from a more accurate evaluation of the aesthetic problems in relation to the cost of the project. The deck cantilevers were originally 
cellular in form (a rather expensive form of construction) and they were associated with diaphragms at about $30 \mathrm{ft}$ centres throughout the bridge.

188. The main reason for the original choice of design was that it was felt that the slab size appearance presented by the long sloping web (which is a feature of the final design) was unacceptable. We subsequently decided that the structural complication and extra cost of the original solution was not justified.

189. The elimination of the cellular cantilevers, and substituting the simple slab cantilevers of this form in the final design, greatly simplified the whole design and, in particular, eliminated the diaphragms, which was a great simplification in construction.

190. Mr Lee also raised the question of how far one should consider the aesthetic aspects of the design in relation to the economic and other factors. This is a subject which comes rather within the same category as how many angels can stand on the point of a pin. All we can say is that we felt that the aesthetic aspect was very important. The fact that it was a competition design originally no doubt influenced this but we believe that for any bridge the aesthetic side of the design is of fundamental importance. We were far from blind to the economics of the project, and believe that the final price justifies our assumptions. The lowest tender price for the bridge worked out at $£ 7 / \mathrm{sq}$. $\mathrm{ft}$ and the accepted tender, which was accepted largely because of the cost of the road as opposed to the bridge, was $£ 9 /$ sq. $f t$ which we believe was fairly reasonable for the conditions obtaining.

191. What was really paid for, if any extra was paid over Mr Lee's design, was the greater length of the bridge. The bridge is $360 \mathrm{ft}$ long and $9 \mathrm{ft} 6 \mathrm{in}$. deep as compared with Mr Lee's $240 \mathrm{ft}$ long and about $11 \mathrm{ft}$ deep. This shallow depth cost a certain amount of money in heavy prestressing. With regard to Mr Lee's other point, the bridge does not have excessive torsional strength. In fact, we have just enough to make the bridge stand up.

192. The question of the vertical deflexion at the end of the cantilever was also raised by $\mathrm{Mr}$ Lee. We had $1 \mathrm{in}$. during construction. We have not taken any measurement since completion of the bridge, but we have every reason to believe that it is something less than that now. The 1 in. occurred at the extreme skew end of the bridge, which is in the verge of the motorway. Beyond this one has the hard shoulder before reaching the actual working part of the bridge, where the vertical movement will be much reduced.

193. Mr Steel raised the question of a welded steel anchor block. During the design we considered various alternatives, and we are satisfied that the solution we have is the cheapest and the only practical one, once the problem of anchoring a 2000 ton prestressing force is presented.

194. Mr Elliott raised the question of transverse bending stresses, for which we used the photo-elastic model. This model was used only to establish the points of contraflexure in the individual elements of the cross section. Having established these, we were able to analyse directly the remaining statically determinate problem. We would suggest that any method used, either computer or model (as in our case), would only be as accurate as the assumptions made at the outset with regard to the method of support.

195. Mr Elliott asked whether it was possible to increase the factor of safety against overturning in the final design as against the original design. The factor of safety against overturning was $2 \cdot 3$ against overturning in the original design, and was 2.75 in the final design. This was achieved by widening the space of the roller bearings from $18-22 \mathrm{ft}$.

196. This shows the great inherent stability of a bridge of this kind. In calculating the factor of safety against overturning, we took account of constructional errors resulting in the centre of gravity being some 6 in. away from the calculated position.

197. On the question of the value or otherwise of competitions, we would say that they are most valuable in that new blood is allowed to come forward and enter 
the arena, whereas previously the scene may have been dominated by firms of long standing who are there, possibly, by virtue of the inertia of the system. Also, competitions are extremely enjoyable.

198. Mr Probert raised many questions. Steel of $0.1 \%$ shrinkage was provided in the piers. We alleviated the shrinkage problems by casting the piers before we stressed the pier base, so that the interconnexion was itself prestressed and not simply the pier base.

199. The sand asphalt was machine laid but there was preliminary hand laying in local low spots.

200. The competition documents referred to Ministry of Transport Memorandum 785, CP 114, CP 115 and BS 153. Clause 3.2.3 of Memorandum 785 refers to $25 \%$ overstress, under HB loading conditions, and this is interpreted as applying to all stresses except 'bending or direct tension', neither of which are permitted to occur under HA or HB loading.

201. Yes, we quoted to the contractor the reaction values we anticipated throughout the stressing operation. These were based on a fairly complicated analysis involving the flexibilities of the falsework and superstructure, and incorporating an estimate of elastic pier settlement. Certain reactions were monitored on hydraulic jacks and were found to behave as predicted. The midspan hog on completion of prestressing was, in the case of both bridges, within $\frac{1}{4}$ in. of that predicted.

202. No allowance for differential shrinkage was made in the design. Vertical shrinkage cracks developed in the webs of the units prior to jointing. After prestressing none of these cracks remained visible.

203. The retightening of the scaffold tubes was judged by hand. Stress measurements on the strand were carried out in detail only on the first three strands and involved only two half days of work. There were no claims for delay on this account. Continuous checking of gauges on the superstructure and falsework was carried out by two members of the resident engineer's staff and two members of the Contractor's staff. The time of readings was arranged so that no delay was caused to the contract, although to do this did involve some rather odd working hours. Young's modulus for the strand was established as the average of all the tests carried out on the coils delivered to site. These varied by $\pm 3 \%$ and individual extensions varied from the calculated value by as much as \pm 3 in. $( \pm 10 \%)$ in extreme cases. However, when all extensions were summed the final aggregate extension was within $1 \%$ of that calculated on the average $E$ value.

204. All calculations in the vicinity of the pier were duplicated in order to determine the range of possible stress conditions resulting from either full, or alternatively zero, contribution of the deck cantilevers. The net box was assumed to be fully functional since it was monolithic with its supporting pier, which was the full width of the bottom flange and continued to the top flange in the form of a solid diaphragm.

205. Mr Rees asked where the subsidence requirements came from. They were stipulated by the Ministry of Transport, but we understand that they originated from the West Riding County Surveyor's office. They have probably wider experience of subsidence conditions than anyone in the country. Because these requirements were so severe we can only conclude that this is the sort of subsidence which they really have in this area. We understand that it is no longer proposed to mine under the bridge in the very near future, but let us hope that mining does eventually take place, because it seems a very great pity to otherwise have wasted so much effort. Mr Rees said that not much rotation was required to cause the bridge to turn over. We believe that this is very true, and that it reflects some credit on us for the fact that it is going to stand up! There are no actual jacks on the site. If it were required to jack, the jacks would have to be brought in specially. There is no real difficulty here, because it would be known well in advance when the area was to be mined.

206. We do not believe that any insuperable problem is posed by the jacking, because there is plenty of room to get the jacks in. The jacks can be linked hydraulic- 
ally and the pressure controlled. We do not think it is particularly important that there should be one jack at one end and two at the other end. One can have two jacks at each end, and this is the system on which we are working. It is intended to take up the jacking movement by means of machined plates.

207. In reply to Mr Cooper's query, only the short beams spanning between the end cantilevers and the abutments are covered with a 14 in. layer of tarmacadam. This is intended to have the effect of preventing minor irregularities caused by the beams racking or twisting under subsidence conditions causing damage to the road surface.

\section{References}

1. TyLeR R. G. Full-scale tests on the Mancunian Way elevated road. Proc. Instn civ. Engrs, 1969 Suppl. 7196 S, 27-72.

2. LeONHARDT, F. Prestressed concrete: design and construction, 2nd revised edition, Ernst, Berlin, 1964. Translated by C. van Amerongen from 2nd edition of Leonhardt's Spannbeton für die Praxis, Ernst, Berlin, 1962.

3. Baxter J. W. et al. The Narrows Bridge, Perth, Australia. Proc. Instn civ. Engrs, 1961, 20 (Sept.) 39-84.

4. NEw D. H. et al. The superstructure of the Tasman Bridge, Hobart. J. Instn struct. Engrs, 1967, 45 (Feb.) 81-90. 